\title{
Social media for collaborative learning
}

\author{
Nur Shamsiah Abdul Rahman ${ }^{1}$, Lina Handayani ${ }^{2}$, Mohd Shahizan Othman ${ }^{3}$, \\ Waleed Mugahed Al-Rahmi ${ }^{4}$, Shahreen Kasim ${ }^{5}$, Tole Sutikno ${ }^{6}$ \\ ${ }^{1}$ Faculty of Computing, Universiti Malaysia Pahang, Malaysia \\ ${ }^{2}$ Faculty of Public Health, Universitas Ahmad Dahlan, Indonesia \\ ${ }^{3}$ Faculty of Computing, Universiti Teknologi Malaysia, Malaysia \\ ${ }^{4}$ Faculty of Education, Universiti Teknologi Malaysia, Malaysia \\ ${ }^{5}$ Faculty of Computer Science and Information Technology, Universiti Tun Hussein Onn Malaysia, Malaysia \\ ${ }^{6}$ Faculty of Industrial Technology, Universitas Ahmad Dahlan, Indonesia
}

\section{Article Info \\ Article history: \\ Received Apr 9, 2019 \\ Revised Sep 9, 2019 \\ Accepted Sep 17, 2019 \\ Keywords: \\ Behavioral intention \\ Collaborative learning \\ Social media \\ TAM \\ UTAUT}

\section{Corresponding Author:}

Nur Shamsiah Abdul Rahman,

Faculty of Computing,

Universiti Malaysia Pahang,

Lebuhraya Tun Razak, 26300 Gambang, Pahang, Malaysia.

Email: shamsiah@ump.edu.my

\begin{abstract}
Research on the field of using social media has gained more importance in the recent days due to the rapid development of social media technologies. Looking at the behavioral intention and attitude of using social media for collaborative learning within Malaysian higher educational institutions and the influencing factors in this regard has received little attention by researchers. The study aims at examining the determinants that affect learners' attitude and behavior intention regarding their use social media to achieve collaborative learning. Such examination is carried out by using the Theory Acceptance Model (TAM) and Unified Theory of Acceptance and Usage of Technology (UTAUT). A total of 243 participants were recruited for this study. The findings indicated that students' attitudes and behavior are strong indicators of their intentions in terms of using social media in collaborative learning.
\end{abstract}

Copyright $@ 2020$ Institute of Advanced Engineering and Science. All rights reserved.

\section{INTRODUCTION}

Currently, social media and its various tools became an integral part in the daily lives of students. Normally, these tools were used for sharing knowledge purpose and to socially communicate with others. Such tools can be also used for the purposes of sharing, promoting and creating online work. Therefore, the use of these tools is said to carry out a wide range of activities supporting collaborative learning $[1,2]$. Recently, higher education levels are witnessing the use of such tools in learning as students discuss and share knowledge and communicate with other individuals through the numerous tools of social media. These tools are also used by the students to have access to learning materials [3].

Cheung et al. [4] Stated that the act of using social media by students to perform or carry out a collective objective can lead to collaborative learning. Other researchers highlighted the bad influence of using such tools as they can distraction students from their academic objectives, cloud their learning performance and even enhance negative sharing $[2,5,6]$. The importance of examining students' behavioral intention and attitude concerning the social media applications' use to assist in learning and teaching purposes goes back to the above mentioned reasons [7-10]. The students' learning performance can be enhanced and distractions can be avoided through learning their attitude and behavior as they use social media [2]. 
Recent years, understanding different reasons behind the use intention among student in using social media received much attention as they can be significant indicators of how to use social media in learning within higher educational level in particular [7]. For many years have received much attention to the factors that might have a role behind the social media acceptance for learning by students and their acceptance of such tools [7, 11]. Also, previous research highlighted those factors that might affected on students' attitude and use intention of social media [12]. Regardless of the fact that the different tools of social media received acceptance in terms of use in most universities around the world, there is no general agreement on the different elements that have an impact on students' behavioral intention and attitude in terms of using of social media in a way to achieve collaborative learning. This gab can be found in the research done in Malaysia as it lacks the depth of investigation [13].

A research model integrating both of the TAM and UTAUT is reported in the current study. The study also highlights and examines 12 constructs that can have an influence on the attitude and behavioral intention in reaching a collaborative learning. These elements are perceived usefulness, perceived enjoyment, perceived ease of use, effort expectancy, social influence and facilitating conditions, behavioral intention to use social media, attitude, collaborative learning, social media use, and teaching and learning. The research model and hypotheses are discussed in the second section of this study while the third illustrates the development of data collection tool and the date collected. Part 4 of the current study present the results and part 5 provide a discussion of the results obtained.

\section{RESEARCH MODEL}

As illustrated in Figure 1, twelve factors were presented for the proposed research model namely perceived ease of use; perceived enjoyment; perceived usefulness; performance expectancy; social influence; effort expectancy; attitude towards use; facilitating conditions; social media use; behavioral intention; teaching and learning and collaborative learning.

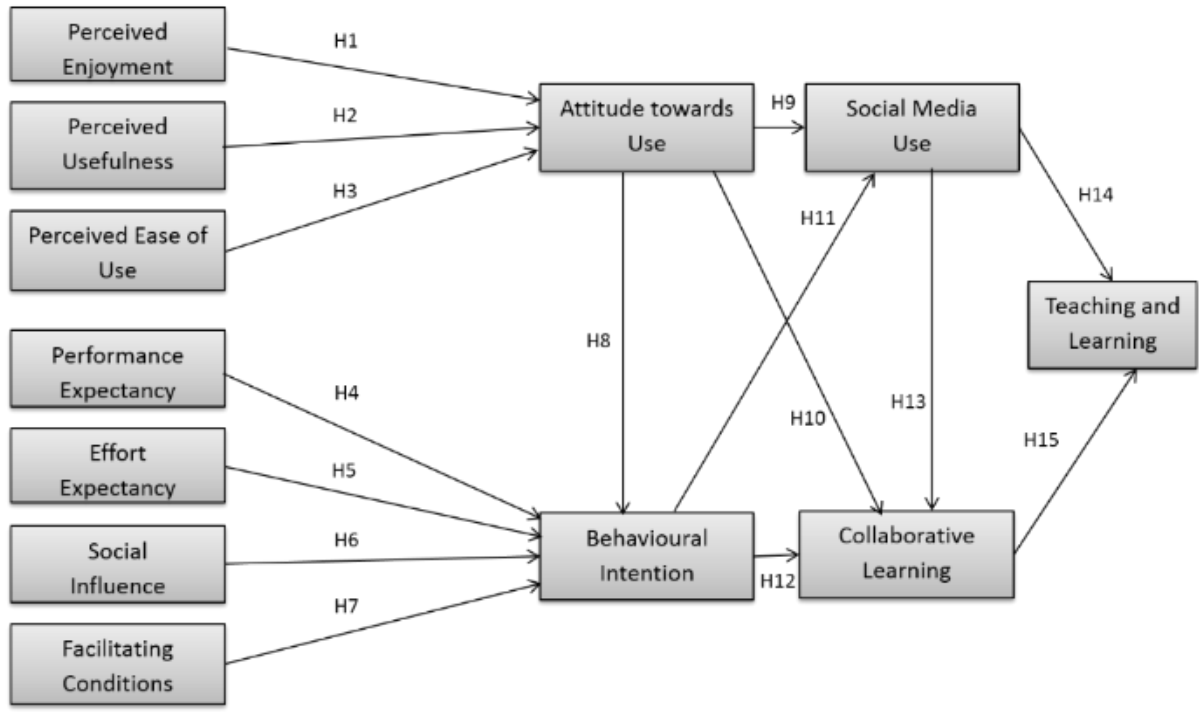

Figure 1. Research model

\subsection{Perceived enjoyment (PEN)}

PEN has been described by Allam et al. [12] as the level of enjoyment perceived by students as they participate in activities by using social media. This concept is considered as integral factor and also used as a predictor of the intention to use the system $[12,14]$. Past work mentioned that attitude can be influenced by perceived enjoyment [15]. In other words, the user's attitude toward the use of certain activity can be positive when this user finds it enjoyable to do this activity. Social media has been defined by some researchers as the pleasure-oriented information system that pushes the users to continuously use it. This is accompanied with high level motivation by the users with a high level of enjoyment $[16,17]$. This introduces the first hypothesis as follows:

H1: The attitude is positively influenced by perceived enjoyment 


\subsection{Perceived usefulness $(P U)$}

It is suggested by the technology acceptance model that perceived usefulness is considered the greatest force behind a person's intention of suing information technology [18, 19]. Mazman and Usluel [20] pinpointed that the behavioural intention can be greatly effected by perceived usefulness. Other went to describe perceived usefulness as the catalyst when it comes to the adoption of social media in educational settings. In the current study, the PU is referred to as the tools to measure students' belief in using social media. It is also said to influence students' attitudes as it is used in collaborative learning. This introduced the second hypothesis as follows:

H2: The attitude can be positively influenced by the perceived of usefulness.

\subsection{Perceived ease of use (PEU)}

It was highlighted by Elkaseh et al. [21] and Labib \& Mostafa [15] that PEU can determine person's attitude towards the use of technology. Studies relating to these two factors were also reported in the previous literature $[8,15,21,22]$. In one of the previous studies discussed about E-Learning, it was found out that both of the students' behavior of using and the attitude was influenced by the PEU [21]. This was supported by Alharbi and Drew [22] who found out the similar result in one study in using the learning management system. This introduced the third hypothesis as follow:

H3: Attitude has a high impact on perceived ease of use.

\subsection{Performance expectancy (PEX)}

It had been reported by Venkatesh et al. [19] That the behavioral intention of using some technologies as found within either involuntary or voluntary settings can be highly determined by performance expectancy. PEX was found to be influenced by behavioral intention within the learning context expectancy [23-24]. This introduces the following hypothesis:

H4: The behavioral intention can be affected by the performance expectancy.

\subsection{Effort expectancy (EE)}

This concept is referred to as the students' perception concerning social media technology use as effortless. It assumed that there are no difficulties or challenges facing students in using social media as their medium of communication for learning. In past research, behavioral intention was proved to be directly influenced by effort expectancy [24]. This point introduced the following hypothesis:

H5: The behavioral intention can be positively influenced by effort expectancy.

\subsection{Social influence (SIN)}

This term is referred to as the measurement by which students perceive other individuals or certain people to trust social to enhance collaborative learning [19]. Previous research on this point found out that others such as peer students, instructors and parents can influence the decision of the students [25]. On light of the above mentioned, this study found that it is significant to include social influence in the proposed model. This introduces the following hypothesis:

H6: The behavioral intention can be highly influenced by social influence.

\subsection{Facilitating conditions (FAC)}

Huang [7] stated that technology adoption can be highly determined by facilitating conditions. This can be due to the reasons that users do not have the training time or they might not be willing to use the technology because of a compatibility problem with the system. Looking at the outcome of some research, it has been reported that behavioral intention has a positive relation with facilitating conditions [23, 26-27]. This introduces the following hypothesis:

H7: The behavioral intention can be highly affected by facilitating conditions.

\subsection{Attitude (ATT)}

According to Yueh et al. [28], individuals' attitude is the reason behind intention. Moreover, the behaviors of individuals can be highly determined by attitude [29]. Previous studies by [13, 21] further highlight that behavioral intention can be determined by attitude. This leads to the following hypotheses:

H8: The behavioral intention can be highly influenced by attitude.

H9: The use of social media can be positively influenced by the attitude.

H10: Attitude has a high impact on collaborative learning. 


\subsection{Behavioral intention to use (BITU)}

This term refers to the students' adoption of applying social media for collaborative learning. Past research found out that the practice of social media in collaborative learning can be influenced by behavioral intention [30]. This leads to the following hypotheses:

H11: The social media use is highly determined by behavioral intention positively affects.

H12: Collaborative learning is highly determined by behavioral intention positively affects.

\subsection{Social media use (SM)}

Students' academic achievement is enhanced by social media a significant platform [31-33]. Through strengthening the creative learning process, social media can enhance collaborative learning. In addition to its role in establishing strong relationships among friends, social media can also lead to thorough understanding of the teaching and learning materials [34]. It can also enhance students' GPA's [35] and foster a lasting retention of information [31]. This leads to the following hypotheses:

H13: Collaborative learning has a high impact with the use of social media.

H14: Teaching and learning has a high impact with the use of social media.

\subsection{Collaborative learning (CL)}

This term used in this study as the interactions and connection between the course content and the students. Through working in groups in constructing knowledge, students can develop learning communities [36]. Through the enhancement of collaboration and communication, such learning communities are assisted by social media. In other words, the practice of social media and the resulting CL can boost the transition of knowledge among students and instructors [37]. This introduces the following hypothesis:

H15: Teaching and learning have positive relationships collaborative learning.

\section{RESEARCH METHOD}

This current study used random sampling and involved 243 undergraduate students took part in this study. Statistical significance was analyzed by using both SPSS-21 and AMOS-23. The present paper aims to study the antecedents which might influence Malaysian university students' decisions of using social media for the purposes of collaborative learning. The data were obtained from the survey approach. The questionnaire items were customized to suit all the research objectives.

The questionnaire survey is of two main sections. Firstly, respondents required to complete demographic information including gender, age, institution and specialization in the first section. Next, section two of the survey included items on the questionnaire measured the different constructs as stated in subsection 2. The questionnaire items were customized from previous related research and underwent slight modification to suits the study environment [38-44]. The piloted results found to be reliable according to Cronbach's alpha results of 0.986 .

\section{RESULTS AND DISCUSSION}

As for demographic information, of the participants who completed the questionnaire were 137 male and 106 female undergraduate students. $77.0 \%$ of the participants were between 21-24 years of age, $16.9 \%$ were between of 18-20 years, 5.8\% were between of 25-29 years and $0.4 \%$ were between of 30-34 years. As for their majors, $61.7 \%$ of the participants were majored in science and technology, $36.6 \%$ were majored in engineering, and $1.6 \%$ were majored in social science. Based on their preferred tools of social media, Facebook was number one with a percentage of $95.5 \%$ while $75.7 \%$ were found to use Instagram and $75.3 \%$ of the participants were using YouTube.

This study utilized Structural Equation Modeling to measure and evaluates measurement model and structural model. The resulting between measurement items and underlying latent construct was demonstrating by measurement model. In addition, correlation among the different measurements was demonstrated by the structural model [45]. In the measurement model analysis, confirmatory factor analysis was used to assess the individual item reliability among varying variables. Hair et al. [46], pinpoint that assessment and re-specification of the measurement model aims at producing the 'best fit' model. The item loadings result analysis for each factors shows the Cronbach alpha $(\alpha)$ value have a good scale of reliability for all constructs were above 0.7 [47]. As suggested by [46, 48], the results for factor loadings are satisfactory as most of these results comply with and exceed 0.50 . Moreover, the average variance extracted (AVE) was also good as all of the values ranged between 0.531 and 0.672 . The values of the construct reliability (CR) were also acceptable as they were all over 0.7 . Table 1 shows item loading for each factor. 
Table 2 illustrates the average variance extracted (AVE) for all constructs. As shown in Table 3, the value of AVE for all constructs has surpassed the other correlation coefficients of the construct which is inline with suggestion by Fornell and Larcker [48]. Diagonal elements are known as the square roots of average variance extracted for the constructs. The correlation coefficients between any two constructs are smaller than the square root of the average variance extracted for the constructs [49]. There was a difference among the constructs of this study which indicate a sufficient discriminant validity for all of them. Thus, the three major tests: reliability, convergent validity, and discriminant validity turned out to be successful which strongly serves the credibility of the study. These results as shown in Figure 2 and Table 2: the hypothesis testing and the structural model analysis.

Table 1. Item loadings for each factors

\begin{tabular}{|c|c|c|c|c|c|c|c|c|c|}
\hline Construct & Item & Loading & $\mathrm{CR}$ & $\alpha$ & Construct & Item & Loading & CR & $\alpha$ \\
\hline \multirow{8}{*}{ PEN } & PE1 & 0.733 & \multirow{9}{*}{0.924} & \multirow{9}{*}{0.927} & \multirow{6}{*}{ FAC } & FC1 & 0.720 & \multirow{6}{*}{0.880} & \multirow{6}{*}{0.887} \\
\hline & PE2 & 0.809 & & & & $\mathrm{FC} 2$ & 0.733 & & \\
\hline & PE3 & 0.765 & & & & FC3 & 0.807 & & \\
\hline & PE4 & 0.742 & & & & $\mathrm{FC} 4$ & 0.771 & & \\
\hline & PE5 & 0.813 & & & & FC5 & 0.708 & & \\
\hline & PE6 & 0.777 & & & & FC6 & 0.704 & & \\
\hline & PE7 & 0.788 & & & \multirow{4}{*}{ ATT } & AT1 & 0.778 & \multirow{4}{*}{0.870} & \multirow{4}{*}{0.869} \\
\hline & PE8 & 0.781 & & & & AT2 & 0.764 & & \\
\hline \multirow{7}{*}{ PU } & PU1 & 0.743 & & & & AT3 & 0.805 & & \\
\hline & PU2 & 0.773 & & & & AT4 & 0.816 & & \\
\hline & PU3 & 0.792 & & & \multirow{5}{*}{ BITU } & BI1 & 0.835 & \multirow{7}{*}{0.925} & \multirow{7}{*}{0.922} \\
\hline & PU4 & 0.839 & 0.926 & 0.927 & & $\mathrm{BI} 2$ & 0.798 & & \\
\hline & PU5 & 0.801 & & & & $\mathrm{BI} 3$ & 0.797 & & \\
\hline & PU6 & 0.794 & & & & BI4 & 0.776 & & \\
\hline & PU7 & 0.856 & & & & BI5 & 0.793 & & \\
\hline \multirow{4}{*}{ PEU } & PEOU1 & 0.800 & \multirow{4}{*}{0.835} & \multirow{4}{*}{0.832} & & BI6 & 0.784 & & \\
\hline & PEOU2 & 0.750 & & & & BI7 & 0.812 & & \\
\hline & PEOU3 & 0.688 & & & \multirow{6}{*}{ SMU } & SMU1 & 0.763 & \multirow{6}{*}{0.911} & \multirow{6}{*}{0.910} \\
\hline & PEOU4 & 0.747 & & & & SMU2 & 0.835 & & \\
\hline \multirow{4}{*}{ PEX } & PEX1 & 0.775 & \multirow{4}{*}{0.857} & \multirow{4}{*}{0.857} & & SMU3 & 0.853 & & \\
\hline & PEX2 & 0.757 & & & & SMU4 & 0.865 & & \\
\hline & PEX3 & 0.792 & & & & SMU5 & 0.778 & & \\
\hline & PEX4 & 0.773 & & & & CL1 & 0.709 & & \\
\hline \multirow{4}{*}{$\mathrm{EE}$} & EE1 & 0.755 & \multirow{4}{*}{0.870} & \multirow{4}{*}{0.870} & \multirow{4}{*}{ CL } & CL2 & 0.711 & \multirow{4}{*}{0.850} & \\
\hline & EE2 & 0.815 & & & & CL3 & 0.721 & & 0.842 \\
\hline & EE3 & 0.801 & & & & CL4 & 0.780 & & \\
\hline & EE4 & 0.795 & & & & CL5 & 0.720 & & \\
\hline & SI1 & 0.756 & & & & TL1 & 0.746 & & \\
\hline & $\mathrm{SI} 2$ & 0.764 & & & & TL2 & 0.750 & & \\
\hline SIN & SI3 & 0.745 & 0.860 & 0.859 & & TL3 & 0.695 & & \\
\hline & SI4 & 0.730 & & & $\mathrm{TL}$ & TL4 & 0.709 & 0.892 & 0.898 \\
\hline & SI5 & 0.717 & & & & TL5 & 0.702 & & \\
\hline Note: & & & & & & TL6 & 0.773 & & \\
\hline CR: Const & ct Reliabi & & & & & TL7 & 0.776 & & \\
\hline
\end{tabular}

Table 2. Discriminant validity

\begin{tabular}{|c|c|c|c|c|c|c|c|c|c|c|c|c|c|}
\hline & AVE & SIN & PU & PEU & PEX & ATT & PEN & $\mathrm{EE}$ & SMU & BITU & TL & CL & FAC \\
\hline SIN & 0.551 & 0.775 & & & & & & & & & & & \\
\hline PU & 0.641 & 0.551 & 0.800 & & & & & & & & & & \\
\hline PEU & 0.558 & 0.707 & 0.709 & 0.856 & & & & & & & & & \\
\hline ATT & 0.626 & 0.636 & 0.665 & 0.834 & 0.799 & 0.857 & & & & & & & \\
\hline PEN & 0.603 & 0.597 & 0.721 & 0.814 & 0.706 & 0.791 & 0.776 & & & & & & \\
\hline $\mathrm{EE}$ & 0.627 & 0.714 & 0.606 & 0.714 & 0.745 & 0.706 & 0.665 & 0.792 & & & & & \\
\hline BITU & 0.639 & 0.715 & 0.620 & 0.766 & 0.726 & 0.711 & 0.666 & 0.717 & 0.797 & 0.830 & & & \\
\hline $\mathrm{TL}$ & 0.542 & 0.574 & 0.625 & 0.753 & 0.756 & 0.700 & 0.670 & 0.634 & 0.754 & 0.670 & 0.798 & & \\
\hline $\mathrm{CL}$ & 0.531 & 0.688 & 0.615 & 0.764 & 0.777 & 0.730 & 0.647 & 0.719 & 0.793 & 0.680 & 0.737 & 0.734 & \\
\hline FAC & 0.550 & 0.755 & 0.557 & 0.690 & 0.770 & 0.729 & 0.694 & 0.786 & 0.715 & 0.799 & 0.664 & 0.729 & 0.741 \\
\hline
\end{tabular}




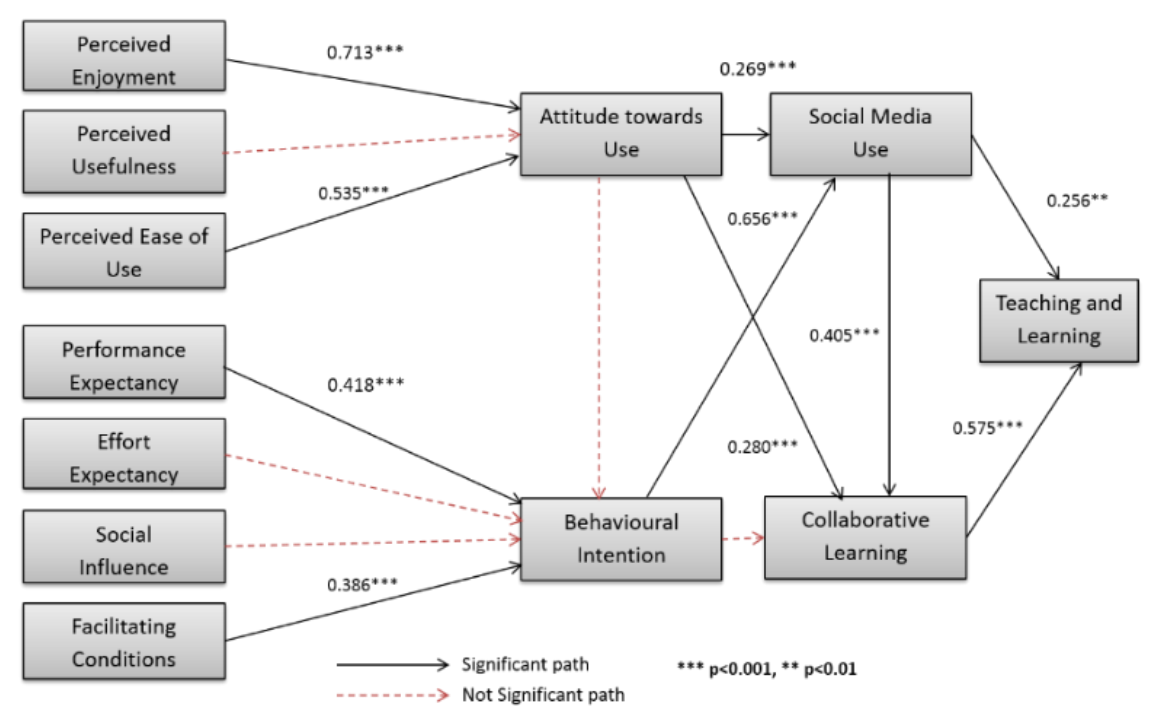

Figure 2. Structural model analysis

Table 3. Results

\begin{tabular}{|c|c|c|c|c|c|c|}
\hline $\mathrm{H}$ & Relation & Estimate & $\mathrm{SE}$ & C.R & $\mathrm{p}$ & Result \\
\hline $\mathrm{H} 1$ & $\mathrm{PEN} \rightarrow \mathrm{ATT}$ & 0.713 & 0.092 & 7.721 & **** & Supported \\
\hline $\mathrm{H} 2$ & $\mathrm{PU} \rightarrow \mathrm{ATT}$ & -0.056 & 0.084 & -0.673 & 0.501 & Not supported \\
\hline H3 & $\mathrm{PEU} \rightarrow \mathrm{ATT}$ & 0.535 & 0.099 & 5.381 & $* * *$ & Supported \\
\hline $\mathrm{H} 4$ & $\mathrm{PEX} \rightarrow \mathrm{BITU}$ & 0.418 & 0.077 & 5.393 & $* * *$ & Supported \\
\hline H5 & $\mathrm{EE} \rightarrow \mathrm{BITU}$ & 0.087 & 0.067 & 1.303 & 0.192 & Not supported \\
\hline H6 & $\mathrm{SIN} \rightarrow \mathrm{BITU}$ & 0.116 & 0.062 & 1.861 & 0.063 & Not supported \\
\hline $\mathrm{H} 7$ & FAC $\rightarrow$ BITU & 0.386 & 0.072 & 5.351 & $* * *$ & Supported \\
\hline $\mathrm{H} 8$ & $\mathrm{ATT} \rightarrow \mathrm{BITU}$ & 0.100 & 0.056 & 1.793 & 0.073 & Not supported \\
\hline H9 & $\mathrm{ATT} \rightarrow \mathrm{SMU}$ & 0.269 & 0.065 & 4.145 & $* * *$ & Supported \\
\hline $\mathrm{H} 10$ & $\mathrm{ATT} \rightarrow \mathrm{CL}$ & 0.280 & 0.063 & 4.425 & $* * *$ & Supported \\
\hline H11 & $\mathrm{BITU} \rightarrow \mathrm{SMU}$ & 0.656 & 0.084 & 7.836 & $* * *$ & Supported \\
\hline $\mathrm{H} 12$ & $\mathrm{BITU} \rightarrow \mathrm{CL}$ & 0.070 & 0.084 & 0.831 & 0.406 & Not supported \\
\hline H13 & $\mathrm{SMU} \rightarrow \mathrm{CL}$ & 0.405 & 0.090 & 4.486 & $* * *$ & Supported \\
\hline $\mathrm{H} 14$ & $\mathrm{SMU} \rightarrow \mathrm{TL}$ & 0.256 & 0.085 & 3.028 & $* *$ & Supported \\
\hline $\mathrm{H} 15$ & $\mathrm{CL} \rightarrow \mathrm{TL}$ & 0.575 & 0.111 & 5.166 & $* * *$ & Supported \\
\hline
\end{tabular}

\section{DISCUSSION}

The current study looked at both attitude and behavior intention to use social media for collaborative learning and aimed at investigating the various factors that might have an impact on them. Based on the outcome of this study (refer Table 3), majority of the hypotheses result were supported with the exception of $\mathrm{H} 2, \mathrm{H} 5, \mathrm{H} 6, \mathrm{H} 8$, and H13. One of the major findings is that attitude to use social media for collaborative learning was strongly influenced by both perceived enjoyment and perceived ease of use providing support to $\mathrm{H} 1$ and $\mathrm{H} 3$. These results correlate satisfactory with Leng et al. [13] Who shared same result in their previous findings. This result confirms students' willingness of using social media tools increases as they find them useful to be used. It is remarkable to mention that $\mathrm{H} 2$ was rejected in this study as attitude was not directly influenced by perceived usefulness.

Another major discovery reported that behavioral intention to use social media was strongly affected by the expectancy performance and facilitating conditions. This finding support hypotheses $\mathrm{H} 4$ and $\mathrm{H} 7 \mathrm{which}$ assumed such a positive relation. Surprisingly, the behavioral intention to use social media was not influenced by effort expectancy, social influence, and attitude. These findings however caused H5, H6 and $\mathrm{H} 8$ to be rejected. This finding also contradicts with the findings by Lwoga and Komba [50] in Tanzania who reported a positive relation between social influence and the students' intention of using e-learning. In addition, the finding of the current study in this regard contradicts with those by Leng et al. [13] Who found that behavioral intention in using social media can be vigorously determined by attitude.

Another finding this study shares is that there is a positive relation between social media usage and both of attitude and behavioral intention to use. This finding support both H11 and H9. This finding also entails the positive relation between collaborative learning and both attitude and social media use providing support to H13 and H10. However, no positive relation was detected between behavioral intention to use and 
collaborative learning causing H12 to be rejected. The last finding this study shares is the positive relation found between teaching and learning and both of social media use and collaborative learning. Another analysis that was mentioned above was performed to investigate the differences between male and female participants. The results regarding the hypothesis testing according to each group of the respondents is apparent in Table 4 and Table 5.

After investigating any differences, it was found that most of the hypothesis-testing results were the same across the two groups except for H8 and H15. As for the similarities, attitude of using social media for collaborative learning was highly determined by perceived enjoyment and perceived ease of use across the two groups. Also, there was no positive relation between usefulness and attitude for both male and female students. As for the differences across the two groups, the results has been found a positive relationship between attitude and behavioral intention in the case of male students. This was the opposite in the case of female students as there was no significant relation between behavioral intention and attitude. Another difference is statistically significant between social media use and teaching and learning for the case of female students and male students.

Table 4. Male's results

\begin{tabular}{|c|c|c|c|c|c|c|}
\hline $\mathrm{H}$ & Relation & Estimate & SE & C.R & $\mathrm{p}$ & Result \\
\hline $\mathrm{H} 1$ & $\mathrm{PEN} \rightarrow \mathrm{ATT}$ & 0.652 & 0.133 & 4.905 & $* * *$ & Supported \\
\hline $\mathrm{H} 2$ & $\mathrm{PU} \rightarrow \mathrm{ATT}$ & -0.062 & 0.122 & -0.508 & 0.611 & Not supported \\
\hline H3 & $\mathrm{PEU} \rightarrow \mathrm{ATT}$ & 0.660 & 0.174 & 3.784 & $* * *$ & Supported \\
\hline $\mathrm{H} 4$ & $\mathrm{PEX} \rightarrow \mathrm{BITU}$ & 0.441 & 0.104 & 4.230 & $* * *$ & Supported \\
\hline H5 & $\mathrm{EE} \rightarrow \mathrm{BITU}$ & 0.089 & 0.092 & 0.958 & 0.338 & Not supported \\
\hline H6 & $\mathrm{SIN} \rightarrow \mathrm{BITU}$ & 0.118 & 0.087 & 1.349 & 0.177 & Not supported \\
\hline $\mathrm{H} 7$ & $\mathrm{FAC} \rightarrow \mathrm{BITU}$ & 0.364 & 0.094 & 3.876 & $* * *$ & Supported \\
\hline H8 & $\mathrm{ATT} \rightarrow \mathrm{BITU}$ & 0.165 & 0.082 & 2.005 & $*$ & Supported \\
\hline $\mathrm{H} 9$ & $\mathrm{ATT} \rightarrow \mathrm{SMU}$ & 0.324 & 0.115 & 2.830 & $* *$ & Supported \\
\hline $\mathrm{H} 10$ & $\mathrm{ATT} \rightarrow \mathrm{CL}$ & 0.251 & 0.086 & 2.913 & $* *$ & Supported \\
\hline H11 & $\mathrm{BITU} \rightarrow \mathrm{SMU}$ & 0.728 & 0.137 & 5.308 & $* * *$ & Supported \\
\hline H12 & $\mathrm{BITU} \rightarrow \mathrm{CL}$ & 0.174 & 0.100 & 1.731 & 0.083 & Not supported \\
\hline H13 & $\mathrm{SMU} \rightarrow \mathrm{CL}$ & 0.263 & 0.096 & 2.750 & $* *$ & Supported \\
\hline H14 & $\mathrm{SMU} \rightarrow \mathrm{TL}$ & -0.058 & 0.128 & 0.128 & 0.641 & Not supported \\
\hline H15 & $\mathrm{CL} \rightarrow \mathrm{TL}$ & 0.972 & 0.232 & 4.186 & $* * *$ & Supported \\
\hline
\end{tabular}

Table 5. Female's Results

\begin{tabular}{|c|c|c|c|c|c|c|}
\hline $\mathrm{H}$ & Relation & Estimate & $\mathrm{SE}$ & C.R & $\mathrm{p}$ & Result \\
\hline $\mathrm{H} 1$ & $\mathrm{PEN} \rightarrow \mathrm{ATT}$ & 0.836 & 0.130 & 6.430 & $* * *$ & Supported \\
\hline $\mathrm{H} 2$ & $\mathrm{PU} \rightarrow \mathrm{ATT}$ & -0.093 & 0.120 & -0.776 & 0.438 & Not supported \\
\hline H3 & $\mathrm{PEU} \rightarrow \mathrm{ATT}$ & 0.447 & 0.116 & 3.841 & $* * *$ & Supported \\
\hline $\mathrm{H} 4$ & $\mathrm{PEX} \rightarrow \mathrm{BITU}$ & 0.279 & 0.119 & 2.343 & $*$ & Supported \\
\hline H5 & $\mathrm{EE} \rightarrow \mathrm{BITU}$ & 0.075 & 0.092 & 0.812 & 0.417 & Not supported \\
\hline H6 & $\mathrm{SIN} \rightarrow \mathrm{BITU}$ & 0.133 & 0.087 & 1.525 & 0.127 & Not supported \\
\hline H7 & FAC $\rightarrow$ BITU & 0.467 & 0.121 & 3.866 & $* * *$ & Supported \\
\hline H8 & $\mathrm{ATT} \rightarrow \mathrm{BITU}$ & 0.049 & 0.072 & 0.673 & 0.501 & Not supported \\
\hline H9 & $\mathrm{ATT} \rightarrow \mathrm{SMU}$ & 0.215 & 0.073 & 2.924 & $* *$ & Supported \\
\hline $\mathrm{H} 10$ & $\mathrm{ATT} \rightarrow \mathrm{CL}$ & 0.280 & 0.086 & 3.267 & $* *$ & Supported \\
\hline H11 & $\mathrm{BITU} \rightarrow \mathrm{SMU}$ & 0.583 & 0.106 & 5.492 & $* * *$ & Supported \\
\hline H12 & BITU $\rightarrow$ CL & 0.090 & 0.128 & 0.704 & 0.481 & Not supported \\
\hline H13 & $\mathrm{SMU} \rightarrow \mathrm{CL}$ & 0.530 & 0.156 & 3.392 & $* * *$ & Supported \\
\hline H14 & $\mathrm{SMU} \rightarrow \mathrm{TL}$ & 0.581 & 0.148 & 3.917 & $* *$ & Supported \\
\hline $\mathrm{H} 15$ & $\mathrm{CL} \rightarrow \mathrm{TL}$ & 0.302 & 0.126 & 2.395 & $*$ & Supported \\
\hline
\end{tabular}

\section{CONCLUSION}

Our research highlighted the factors that might have a significant impact on the attitude of students and behavioral intention to use social media for collaborative learning in Malaysian higher education context. Proposed model used in this study which is combining TAM and UTAUT was credible and reliable and included these factors the relation between them. In general, the attitude was proved to be influenced by perceived enjoyment and perceived ease of use. At the same time, both of performance expectancy and facilitating conditions proved to have a strong impact on behavioral intention. 10 of the hypotheses in this study were supported indicating that the proposed framework can be used to predict the attitude and behavioral intention of students to use social media for collaborative learning. Even though the current study produced significant findings, the study still has some limitations. For example, this study was done on just one institution in Malaysia and this is an invitation to future studies to include other educational institutions. 
Including more than one educational institutions in the study can give the study the advantage of generalizability of the findings. In the future, other research works such as [51-53] will be embedded to enhance our method.

\section{ACKNOWLEDGEMENTS}

This research was made possible by from a grant RDU1803147by Universiti Malaysia Pahang. We are also particularly grateful to Faculty of Computing, UTM for constructive support.

\section{REFERENCES}

[1] Y.-W. Liao, et al., "Exploring the antecedents of collaborative learning performance over social networking sites in a ubiquitous learning context," Computers in Human Behavior, vol. 43, pp. 313-323, 2015.

[2] M. Ali, et al., "Evaluating students information sharing behavior through social media: A pilot study," Australian Journal of Basic and Applied Sciences, vol. 9(19), pp. 94-100, 2015.

[3] J. H. Al-Ammary, et al., "The acceptance of social networking as a learning tools at University of Bahrain," International Journal of Information and Education Technology, vol. 4(2), pp. 208-214, 2014.

[4] R. Cheung and D. Vogel, "Predicting user acceptance of collaborative technologies: An extension of the technology acceptance model for e-learning," Computers \& Education, vol. 53, pp. 160-175, 2013.

[5] G. Tur and V. I. Marín, "Enhancing learning with the social media: student teachers' perceptions on Twitter in a debate activity," New Approach in Educational Research, vol. 4(1), pp. 46-53, 2015.

[6] D. R. George, et al., "How we used two social media tools to enhance aspects of active learning during lectures," Medical Teacher, vol. 35(12), pp. 985-988, 2015.

[7] Y. M. Huang, "Exploring the factors that affect the intention to use collaborative technologies: The differing perspectives of sequential/global learners," Australasian Journal of Educational Technology, vol. 31(3), pp. 278-292, 2015.

[8] L. Abdullah, "Predictors of students intention to use social networking sites: Path analysis," Journal of Next Generation Information Technology, vol. 4(3), pp. 74-80, 2013.

[9] E. T. Lwoga, M. Komba, "Understanding University students' behavioural continued intentions to use e-learning in Tanzania," Proceedings and report of the 7th UbuntuNet Alliance annual conference, pp. 167-188, 2014.

[10] O. B. Ayoade, "Factors influencing students' behavioural intention to adopt and use mobile learning in higher educational institutions in Nigeria: An example of Ekiti State University, Ado-Ekiti," International Journal of Emerging Technology and Advanced Engineering, vol. 5(4), pp. 307-313, 2015.

[11] M. Thongmak, "Factors determining learners' acceptance of facebook in higher education classroom," Knowledge Management \& E-Learning, vol. 6(3), pp. 316-331, 2014.

[12] H. Allam, et al., "Exploring factors impacting users' attitude and intention towards social tagging systems," 2012 In Hawaii International Conference on System Sciences, pp. 3129-3138, 2012.

[13] G. S. Leng, et al., "An Exploration of social networking sites (SNS) adoption in Malaysia using technology acceptance model (TAM), theory of planned behavior (TPB) and intrinsic motivation," Journal of Internet Banking and Commerce, vol. 16 (2), pp. 1-27, 2011.

[14] N. S. Abdul Rahman, et al., "Exploring the use of social media tools among students for teaching and learning," Journal of Theoretical and Applied Information Technology, vol. 91(1), pp. 49-59, 2016.

[15] N. M. Labib and R. H. A. Mostafa, "Determinants of social networks usage in collaborative learning: Evidence from Egypt," Procedia Computer Science, vol. 65, pp. 432-441, 2015.

[16] A. R. Waleed, et al., "Use of E-Learning by University Students in Malaysian Higher Educational Institutions: A Case in Universiti Teknologi Malaysia," IEEE Access, vol. 99, pp. 1-1, 2018.

[17] D. Sledgianowski and S. Kulviwat, "Social network sites, antecedents of user adoption and usage," AMCIS 2008 Proceeding, 2009.

[18] V. Venkatesh and F. D. Davis, "A theoretical extension of the technology-acceptance model: Four longitudinal field studies," Management Science, vol. 46(2), pp. 186-204, 2000.

[19] V. Venkatesh, et al., "User acceptance of information technology: Toward a unified view," MIS quarterly, pp. 425-478, 2003.

[20] S. G. Mazman and Y. K. Usluel, "Modeling educational usage of Facebook," Computers \& Education, vol. 55(2), pp. 444-453, 2010.

[21] A. Elkaseh, et al., "Perceived Ease of Use and Perceived Usefulness of Social Media for e-Learning in Libyan Higher Education: A Structural Equation Modeling Analysis," International Journal of Information and Education Technology, vol. 6(3), 2016.

[22] S. Alharbi and S. Drew, "Using the Technology Acceptance Model in Understanding Academics' Behavioural Intention to Use Learning Management Systems," International Journal of Advanced Computer Science and Applications, vol. 5(1), 2014.

[23] T. D., Thomas, et al., "The utility of the UTAUT model in explaining mobile learning adoption in higher education in Guyana," International Journal of Education and Development Using Information and Communication Technology, vol. 9(3), pp. 71-85, 2013.

[24] J. K. Arthur, et al., "A conceptual framework for the Adoption of Social Network Technologies (SNTs) in Teaching - case of Ghana, " International Journal of Computer Science Issues, vol. 10(5), no 2, pp. 70-74, Sep 2013. 
[25] A. Abu-al-aish and S. Love, "Factors Influencing Students' Acceptance of M-Learning : An Investigation in Higher Education," The International Review of Research in Open and Distance Learning, vol. 14(5), pp. 83-108, 2013.

[26] R. Echeng, et al., "Acceptance of Web 2.0 in learning in higher education: a case study Nigeria," International Journal of Advanced Computer Science and Applications, vol. 4(10), 2013.

[27] S. Ismail, "International students' acceptance on using social networking site to support learning activities," International Journal for the Advancement of Science \& Arts, vol. 1(2), pp. 90-99, 2010.

[28] P. Yueh, et al., "Exploring factors affecting students' continued Wiki use for individual and collaborative learning: An extended UTAUT perspective," Australasian Journal of Educational Technology, vol. 31(1), 2015.

[29] I. Ajzen and M. Fishbein, Understanding attitudes and predicting social behaviour, Englewood Cliffs, NJ: Prentice-Hall, 1980.

[30] W. M. Al-Rahimi, et al., "Using TAM model to measure the use of social media for collaborative learning," International Journal of Engineering Trends and Technology, vol. 5(2), pp. 90-95, 2013.

[31] K. Tarantino, et al., "Effects of Student Engagement with Social Media on Student Learning : A Review of Literature," The Journal of Technology in Student Affairs, pp. 1-13, 2013.

[32] N. Selwyn, et al., "Education 2.0? Designing the web for teaching and learning," Teaching and Learning Research Programme, 2008.

[33] W. M. Al-Rahmi and M. S. Othman, "Evaluating student's satisfaction of using social media through collaborative learning in higher education," International Journal of Advances in Engineering \& Technology, vol. 6(4), pp. 1541-1551, 2013.

[34] B. Chen and T. Bryer, "Investigating instructional strategies for using social media in formal and informal learning," The International Review of Research in Open and Distributed Learning, vol. 13(1), pp. 87-104, 2012.

[35] R. Junco, "Student class standing, Facebook use, and academic performance," Journal of Applied Developmental Psychology, vol. 36, pp. 18-29, 2015.

[36] M. K. Kabilan, et al., "Facebook: An online environment for learning of English in institutions of higher education?," Internet and Higher Education, vol. 13, pp. 179-187, 2010.

[37] W. M. Al-Rahmi, et al., "Social media for collaborative learning and engagement: Adoption framework in higher education institutions in Malaysia," Mediterranean Journal of Social Sciences, vol. 6(3), pp. 246-252, 2015.

[38] H. Ajjan and R. Hartshorne, "Investigating faculty decisions to adopt Web 2.0 technologies: theory and empirical tests," The Internet and Higher Education, vol. 11(2), pp. 71-80, 2008.

[39] O. Kwon and Y. Wen, "An empirical study of the factors affecting social network service use," Computers in Human Behaviour, vol. 26, pp. 254-263, 2010.

[40] M. Igbaria, et al., "Personal computing acceptance factors in small firms: A structural equation model," MIS Quarterly, vol. 21(3), pp. 279-302, 1997.

[41] R. Echeng, et al., "Acceptance of Web 2.0 in learning in higher education: a case study Nigeria," International Journal of Advanced Computer Science and Applications, vol. 4(10), 2013.

[42] T. Escobar-Rodríguez, et al., "Factors that influence the perceived advantages and relevance of Facebook as a learning tool: An extension of the UTAUT," Australasian Journal of Educational Technology, vol. 30(2), 2014.

[43] J. Carlos, et al., "Examining the technology acceptance model in the adoption of social networks," Journal of Research in Interactive Marketing, vol. 5(2/3), pp. 116-129, 2011.

[44] R. A. Sanchez, et al., "Students perceptions of Facebook for academic purposes," Computer Education, vol. 70(1), pp. 138-149, 2014.

[45] A. Zainuddin, Structural Equation Modeling using AMOS Graphic, UiTM Press, 2013.

[46] J. F. Hair, et al., Multivariate data Analysis, (7th ed.), New Jersey: Upper Saddle River, Pearson Prentice Hall, 2010.

[47] R. P. Bagozzi, "Evaluating Structural Equation Models with Unobservable Variables and Measurement Error: A Comment," Journal of Marketing Research, vol. 18(3), pp. 375-381, 1998.

[48] C. Fornell and D. F. Larcker, "Evaluating structural equation models with unobservable variables and measurement error," Journal of Marketing Research, pp. 39-50, 1981.

[49] P. Bentler and D. Bonett, "Significance tests and goodness of fit in the analysis of covariance structures," Psychological Bulletin, vol. 88(3), pp. 588-606, 1980.

[50] E. T. Lwoga and M. Komba, "Understanding University students' behavioural continued intentions to use e-learning in Tanzania," Proceedings and report of the 7th UbuntuNet Alliance annual conference, pp. 167-188, 2014.

[51] Mahdin H., Senan N., Kasim S., Ibrahim N., and Abdullah N. A., "Teaching computer programming to IPAD generation," In: International Integrated Engineering Summit (IIES 2014), 2014.

[52] Rahman M. H. A., Phon D. N. E., Utama N. I., Yahaya N., Halim N. D. A., Kasim S., "Sense of Presence and Learning Satisfaction among Students of Different Age Groups in a 3-D Virtual World," International Journal on Advanced Science, Engineering and Information Technology, vol. 9(2), pp. 711-716, 2019.

[53] Rahman M. H. A., Utama N. I., Ali M. B., Halim N. D. A., and Kasim S., "The Effect of Augmented Reality on Spatial Visualization Ability of Elementary School Student," International Journal on Advanced Science, Engineering and Information Technology, vol. 9(2), pp. 624-629, 2019. 